\title{
Concepções e Práticas de Psicólogos Escolares e Docentes acerca da Inclusão Escolar
}

\author{
Fabíola de Sousa Braz-Aquino \\ Universidade Federal da Paraíba, PB, Brasil.
}

\author{
Ingrid Rayssa Lucena Ferreira \\ Universidade Federal da Paraíba, PB, Brasil.
}

\author{
Lorena de Almeida Cavalcante \\ Universidade Federal da Paraíba, PB, Brasil.
}

\begin{abstract}
Resumo: A literatura refere que, embora a matrícula e permanência de todo e qualquer aluno seja assegurada por inúmeros dispositivos jurídicos, verificam-se, no contexto brasileiro, atrasos e desafios para alcançar uma inclusão escolar satisfatória. Observa-se, muitas vezes, a inserção de crianças com necessidades educacionais especiais sem que a escola desenvolva condições físicas e de apoio favoráveis para recebê-las ou sem que objetive potencializar as habilidades destas crianças. Frente ao exposto, considerou-se pertinente analisar concepções e práticas de psicólogos escolares e docentes da cidade de João Pessoa acerca da inclusão escolar. Para tanto, realizaram-se entrevistas semiestruturadas, baseadas na literatura da área escolar, com quinze psicólogos e quinze docentes de escolas públicas. Os resultados revelaram que, embora a maioria dos docentes e psicólogos mostre-se favorável à inclusão escolar, suas ações ainda se encontram distantes da perspectiva inclusiva defendida por pesquisadores e profissionais que se debruçam sobre esta questão.
\end{abstract}

Palavras-chave: Inclusão Escolar, Professores, Psicologia Escolar.

\section{Conceptions and practices, on school inclusion, of school psychologists and teachers}

\begin{abstract}
Literature refers that, although enrollment and permanence in school are assured by many legal devices to all and any student, the Brazilian context is still dealing with delays and challenges to achieve a satisfactory school inclusion. It is often observed the insertion of children with special educational needs without the development, by schools, of favorable physical and supportive conditions to receive them, or without a real aim to potentiate their abilities. Based on the exposed, it was considered pertinent to analyze conceptions and practices of João Pessoas's school psychologists and teachers. For that, were realized semi structured interviews, based on School Psychology's literature, with fifteen school psychologists and fifteen teachers of public institutions. The results reveled that, although most teachers and psychologists show themselves favorable to school inclusion, their practices still distant of the inclusive perspective defended by researchers and professionals who have studied this question.
\end{abstract}

KeYwords: School Inclusion, Teachers, School Psychology. 


\title{
Conceptos y prácticas de profesores y psicólogos escolares sobre inclusión escolar
}

\begin{abstract}
Resumen: La literatura señala que, aunque la matrícula y la retención de todos los alumnos está garantizada por numerosas disposiciones legales, en realidad en el contexto brasileño, persisten retrasos y dificultades para lograr una inclusión escolar satisfactoria. A menudo es observada la inclusión de niños con necesidades educativas especiales sin el desarrollo previo de soporte físico y de condiciones favorables para recibirlos, o sin el propósito de mejorar las habilidades de estos niños, por parte de la escuela. Con base en esto, se consideró oportuno analizar los conceptos y las prácticas de los psicólogos escolares y los maestros de la ciudad de João Pessoa. Para eso, se realizaron entrevistas semiestructuradas, con base la literatura sobre Psicología Escolar, a 15 psicólogos escolares y 15 maestros de escuelas públicas. Los resultados revelaron que aunque la mayoría de los profesores y los psicólogos se muestra a favor de la inclusión escolar, sus acciones están lejos de la perspectiva inclusiva defendida por los investigadores y profesionales que se centran en este tema.

Palabras clave: Inclusión Escolar, Profesores, Psicología Escolar.
\end{abstract}

\section{Introdução}

No Brasil, a matrícula e permanência de todo e qualquer aluno é assegurada por dispositivos jurídicos, tais como a Lei de Diretrizes e Bases da Educação, o artigo no 208 da Constituição Federal de 1988 e as Diretrizes Nacionais para a Educação Especial na Educação Básica. No entanto, observase, muitas vezes, a inserção de crianças com necessidades educacionais especiais (NEE) sem que a escola tenha condições físicas ou de apoio favoráveis para recebê-las. Além disso, verifica-se a manutenção de práticas segregacionistas e marcadas por assistencialismo, o que inviabiliza a proposta de uma "Educação para todos” (Angelucci \& Lins, 2007; Crochík, Casco, Ceron, \& Catanzaro, 2009; Guiné, 2004; Luiz, Bortoli, Floria-Santos, \& Nascimento, 2008; Melo, \& Martins, 2007; Schruber, \& Cordeiro, 2010;).

No âmbito da Psicologia Escolar Educacional, estudiosos (Angelucci, \& Lins, 2007; Facci, \& Eidt, 2011; Guzzo, 2008; 2011; Souza, \& Rocha, 2008) afirmam que, dentre os fatores que dificultam a inclusão escolar, encontram-se o desconhecimento ou o conhecimento superficial por parte de agentes escolares dos referidos dispositivos jurídicos. Ademais, destacam o desconhecimento teórico e prático, pois ainda há currículos de formação generalistas que proporcionam uma compreensão distanciada do processo de ensino-aprendizagem e da inclusão escolar. Para mudar este quadro, ressalta-se que uma formação acadêmica coerente com o contexto de atuação do psicólogo é um dos primeiros passos para incluir todos os alunos nas escolas regulares brasileiras.

A partir das situações vividas nos contextos escolares, vários pesquisadores (Cavallari; 2010; Crochíket. al., 2009; Kafrouni, \& Pan 2001; Wanderer, \& Pedroza, 2010) consideram que outro obstáculo frequente para a efetivação do processo de inclusão consiste na negação das diferenças individuais. Esta postura é atribuída a uma ideologia homogeneizante, ao medo diante da diferença, a possíveis preconceitos, à crença em mitos e à preocupação excessiva com o sucesso escolar. A este respeito, concorda-se com Batista e Enumo (2004), Fragoso e Casal (2012) e Sekkel, Zanelatto e Brandão (2010), que a escola é o espaço ideal para que as crianças se desenvolvam social, emocional e academicamente. Conforme acrescentam, as diferenças devem ser reconhecidas, trabalhadas e transformadas com criatividade pelos agentes escolares, tais como psicólogos escolares, pedagogos e docentes.

Outros aspectos relevantes no processo de inclusão escolar, segundo Carvalho (1993), Crochík et al. (2009) e Leonardo (2008), são os aspectos socioculturais e ideológicos, que influenciam o modo como as diferenças e a inclusão são vivenciadas na escola. De acordo com o primeiro autor, frequentemente se "estigmatiza e marginaliza os que fogem aos padrões comportamentais usuais, considerando-os como incapazes produtivamente, e, portanto, 
desviantes" (p. 93), atitude que pode gerar resistências ao processo de inclusão por parte dos agentes escolares. Desta forma, segundo os referidos autores qualquer ação do Psicólogo Escolar comprometido com o respeito e aceitação das diferenças implica trabalhar essas resistências.

Ao analisar a questão da inclusão escolar, defende-se a importância dos aspectos socioculturais, segundo os quais características relativas à linha de desenvolvimento natural, a exemplo de déficits ou danos cerebrais, podem ser modificados por meio da interação social. Retomando pressupostos gerais vygotskyanos, consideram-se a plasticidade cerebral e a importância da mediação no sentido de promover a transição da zona de desenvolvimento potencial para a zona de desenvolvimento real. Em seus escritos sobre a Defectologia, Vygotsky (1997) afirmou que "todo defecto crea los estímulos para elaborar una compensación” (p. 14). Este autor sustentava que não seria suficiente estabelecer o nível de comprometimento da criança com deficiência ou seus processos de compensação sem que seu devir, suas vivências, também fossem considerados.

Na perspectiva de promoção da inclusão escolar, a Psicologia tem uma grande responsabilidade, uma vez que, como expõe Martínez (2009), há um “[...] compromisso dos psicólogos com a transformação dos processos educativos, com a efetivação das mudanças necessárias que demanda a melhoria da qualidade da educação no país" (p. 169). Diante do exposto, considera-se que a conscientização dos psicólogos acerca de seu papel frente à inclusão de estudantes com necessidades educacionais especiais no âmbito educacional deve ter início desde a graduação (Pletsch, 2009; Schruber, \& Cordeiro, 2010).

Concorda-se também com Fleith (2011), que considera que o psicólogo escolar pode ser um forte agente transformador quando obtém conhecimento do seu papel e de como realizá-lo. Este entendimento possibilita a promoção de ações que destaquem o respeito às diferenças, o que pode ajudar a construir um ambiente favorável à inclusão, por meio do trabalho integrado com os demais agentes escolares, tanto no sentido de promover reflexões como de delinear estratégias interventivas.

Destaca-se como importante que os psicólogos escolares estabeleçam parcerias com os demais agentes educativos, principalmente com docentes e pedagogos, no sentido de ajudá-los a diversificar e aprimorar os métodos de ensino. Deste modo, práticas inclusivas seriam contempladas e desenvolver-se-iam habilidades sociais que oportunizem um melhor relacionamento com os estudantes, principalmente aqueles que apresentam queixas escolares e/ou necessidades educacionais especiais (Almeida-Verdu, Fernandes, \& Rodrigues, 2002; Silva, \& Mendes, 2012).

Estudiosos têm realizado levantamentos acerca de como ocorre a inclusão de alunos com necessidades educacionais especiais no ensino regular brasileiro (Briant, \& Oliver, 2012; Sant'Ana, 2005) e questionam se o direito viabilizado por dispositivos legais à educação em ensino regular é suficiente para assegurar o desenvolvimento e a aprendizagem adequados de alunos com necessidades educacionais especiais. Outros autores (Melo, \& Martins, 2007) consideram aspectos para além da legislação, destacando como os profissionais da educação percebem e enfrentam esta realidade. Nesta linha de pensamento, concorda-se com Dazzani (2010) acerca da importância da conscientização dos agentes escolares para que se compreenda que as concepções acerca de como os alunos com necessidades educacionais especiais aprendem influenciam suas práticas pedagógicas junto a este grupo. Neste ponto de vista, Barroco e Souza (2012) ratificam que existe uma relação entre as concepções e práticas dos profissionais e que estas formas de pensar e agir se configuram em resposta a um contexto histórico e sociocultural específico.

A presente pesquisa objetivou conhecer concepções e práticas de psicólogos escolares e docentes de instituições públicas de ensino da cidade de João Pessoa-PB, considerando o impacto destas concepções nas ações cotidianas desses profissionais junto a escolares com necessidades educacionais especiais.

\section{Método}

\section{Materiais e técnicas de coleta dos dados}

Para conhecer as concepções e práticas de inclusão no sistema regular público de ensino, foram realizadas, com os (as) psicólogos (as) e docentes, entrevistas semiestruturadas, formuladas com base em uma revisão da literatura da área. Além disso, foram utilizados, lápis, papel, caneta e gravador de voz e computador.

\section{Procedimentos éticos e de coleta de dados}

A pesquisa foi apreciada pelo Comitê de Ética em Pesquisa com Seres Humanos do Centro de Ciên- 
cias da Saúde da Universidade Federal da Paraíba (CCS-UFPB), sendo aprovada com o Protocolo $\mathrm{n}^{\circ}$ 0191/12, CCAE: 03274112.70000.5188. Em seguida, a pesquisadora contatou os gestores das instituições escolares por telefone, a fim de explicitar os objetivos do estudo e solicitar permissão para realizar as entrevistas com os (as) psicólogos (as) e docentes das escolas. A participação desses profissionais na pesquisa foi condicionada à assinatura do Termo de Consentimento Livre e Esclarecido e as entrevistas ocorreram em locais reservados da instituição, estando presentes apenas o (a) entrevistado (a) e a pesquisadora.

\section{Participantes}

Participaram deste estudo quinze psicólogos (as) e quinze docentes de escolas públicas do sistema regular de nível Fundamental I, em João Pessoa-PB. Dentre os (as) psicólogos (as): a) 14 eram do sexo feminino e um, do masculino; b) o período em que concluíram a graduação variou de 1985 e 2010; c) houve a predominância da faixa etária de 40 a 50 anos (49\%), com idade mínima de 26 anos e idade máxima de 66 anos; d) o tempo médio de atuação na área foi de 14,5 anos, variando de 3 a 28 anos de atuação; e) em relação à área de supervisão, cinco entrevistados fizeram estágio em Psicologia Educacional, oito em Psicologia Clínica e dois em Psicologia Social; f) $60 \%$ dos participantes também atuavam como professores em outras escolas e 6,6\% com supervisão educacional. Quanto ao grupo de docentes: a) todas eram do sexo feminino; b) o período em que concluíram a graduação variou de 1994 a 2010, havendo também três profissionais que não recordaram o ano de conclusão de curso e uma que era acadêmica do curso de Pedagogia; c) houve a predominância da faixa etária de 30 a 40 anos, com idade mínima de 30 anos e idade máxima de 55 anos; d) o tempo médio de atuação na área foi de 15,4 anos, variando de um a 30 anos de atuação; e) 11 possuíam formação em Pedagogia, um em Psicologia, um em História e um possuía graduação em andamento em Pedagogia. Sete docentes realizaram especializações em psicopedagogia, administração escolar, ensino de ciências, pedagogia sexual e ensino de jovens e adultos; f) Cinco docentes realizaram supervisão em orientação e supervisão educacional, dois em educação e as demais em administração escolar, ensino de jovens e adultos, ensino fundamental I, ensino fundamental II, clínica do adolescente e do adulto, língua inglesa e portuguesa e educação especial, não sendo mencionada a docente que possuía ensino superior incompleto; g) $60 \%$ das docentes trabalhavam como professoras em outras escolas.

\section{Análise dos dados}

Os dados obtidos foram analisados seguindo as diretrizes do método de categorização de conteúdo proposto por Bardin (2008). Para tanto, realizou-se inicialmente a transcrição literal das entrevistas e, em um segundo momento, uma leitura flutuante das falas dos respondentes. Em seguida, iniciou-se o processo de categorização, no qual foram identificadas as falas comuns a todas as entrevistas e levantadas as frequências das mesmas, buscando ainda identificar, nas falas dos participantes, argumentos, explicações ou contradições que melhor revelassem as percepções e práticas destes profissionais no âmbito da inclusão escolar de alunos com necessidades educacionais especiais. Os resultados obtidos a partir desta análise foram discutidos à luz de estudos e pesquisas no campo Escolar Educacional relativo à temática da inclusão escolar, tendo como objetivos específicos identificar: os grupos de alunos com necessidades educacionais especiais; as concepções sobre inclusão dos profissionais; os referenciais teóricos que fundamentam a prática dos mesmos; como os psicólogos descrevem a percepção da comunidade escolar e das famílias frente à inclusão escolar; e as ações realizadas pelas escolas, por psicólogos e por docentes frente à inclusão escolar.

\section{Resultados e discussão}

Inicialmente, foram levantados os principais grupos de estudantes com necessidades educacionais especiais com os quais lidavam os docentes e psicólogos escolares entrevistados. As análises permitiram verificar que apenas três docentes possuíam alunos com necessidades educacionais especiais, sendo mencionadas: surdez (35.,\%), baixa visão (14,3\%) e deficiência intelectual; Síndrome de Down, Síndrome de Asperger, deficiência física, deficiência motora, Transtorno do Déficit da Atenção e hiperatividade $(7,1 \%$ cada).

O grupo de psicólogos, relatou casos de deficiência intelectual (33,4\%), autismo (19\%), surdez (14,3\%), deficiência física (14,3\%), Síndrome de Down $(9,5 \%)$, dificuldades de aprendizagem $(9,5 \%)$ e, em menor frequência, Síndrome de Asperger, 
Transtorno Global do Desenvolvimento, mudez seletiva, deficiência motora, depressão infantil, hiperatividade, problemas comportamentais, paralisia cerebral e baixa visão. Apenas um profissional não lidava com alunos com NEE.

Destaca-se que os psicólogos entrevistados também relataram a existência de alunos que supõem apresentar deficiências ou dificuldades na escolarização, como ilustra o trecho a seguir: “[...] esse parece ter um leve retardo mental ou déficit de atenção, mas, como a gente também não pode fechar o diagnóstico, foi solicitado à mãe que leve às profissionais para fazer uma avaliação". Estas falas acerca dos chamados alunos "sem laudo" podem indicar, como afirma Meira (2003), o uso inadvertido de rótulos no contexto escolar, uma prática que caracteriza a denominada patologização do aluno. Frente a esta realidade, adverte-se para as consequências de uma "classificação" sem que haja de fato uma investigação aprofundada e multidisciplinar acerca da demanda em questão.

Concorda-se com Barbosa e Moreira (2009) que, mesmo havendo um diagnóstico, a referência a estudantes com necessidades educacionais especiais não deve conduzir à rotulação da criança, mas contribuir para que se problematizem e elaborem intervenções frente a sua situação. A respeito da tendência de rotular os alunos de forma inadvertida, considera-se como essencial o desenvolvimento de uma intervenção contextualizada, a partir da conscientização dos psicólogos sobre o papel que podem desempenhar frente à inclusão de estudantes com necessidades educacionais especiais nos contextos educacionais, bem como de sua importância para mobilizar reflexões e ações por parte de agentes escolares e familiares no sentido de repensar e romper com generalizações, homogeneizações e estereótipos referentes a crianças com necessidades educacionais especiais. Estes aspectos devem ser trabalhados na formação acadêmica desde a graduação, podendo-se também promover a formação continuada para os psicólogos em exercício (Pletsch, 2009; Schruber \& Cordeiro, 2010).

A segunda temática investigada consistiu nas concepções dos psicólogos escolares e docentes entrevistados acerca da inclusão escolar. Foram mencionados impedimentos ao processo de inclusão escolar (43,0\% dos psicólogos e 57,1\% dos docentes), concepções favoráveis (36,6\% dos psicólogos e 39,3\% dos docentes), concepções desfavoráveis (14,6\% dos psicólogos e 7,1\% dos docentes) e a consideração da inclusão escolar como um desafio $(4,8 \%$ dos psicólogos escolares).

Os impedimentos ao processo de inclusão escolar se referiam à falta de preparo/capacitação profissional, aspectos relativos à estrutura física da escola ou falta de investimentos na educação por parte do Governo ou das Secretarias. Já os posicionamentos favoráveis à inclusão podem ser exemplificados por falas como "a inclusão é um processo de humanização, eu vejo é humanizar o trabalho escolar". Os relatos que demonstraram concepções desfavoráveis à inclusão escolar englobam respostas como "a gente sofre muito [...] porque a gente tem que primeiramente desconstruir [...] e tem anos e anos que tá construído, é muito difícil”. Por fim, a consideração da inclusão escolar como um desafio é ilustrada por discursos como "desafio que, junta, a equipe a gente vai tentando caminhar e melhorar a vida daquele aluno dentro da escola".

De acordo com os relatos acima, observa-se que a inclusão escolar tem encontrado considerável receptividade entre os psicólogos e docentes entrevistados, refletindo o discurso que o contexto acadêmico e a mídia têm feito acerca da importância da inserção de alunos com NEE na escola. Entretanto, verificou-se também que ainda são muitas as dificuldades para que a inclusão escolar ocorra de modo a beneficiar o desenvolvimento e a aprendizagem dos referidos alunos, a despeito da existência de documentos oficiais como as Diretrizes Nacionais para a Educação Especial na Educação Básica e a Política Nacional de Educação Especial na Perspectiva da Educação Inclusiva.

As dificuldades apontadas pelos entrevistados também são descritas por Crochík et al. (2009), Guiné (2004), Sant'Ana (2005) e Sekkel et al. (2010). Frente a elas, considera-se pertinente verificar se as agências formadoras de psicólogos e docentes ainda atêm-se a currículos que proporcionam uma compreensão distanciada do processo de ensino-aprendizagem e, em decorrência disso, não formam suficientemente para o trabalho com as demandas escolares, dentre elas a diversidade e a inclusão escolares. (Facci \& Eidt, 2011; Guzzo, 2008; 2011; Souza, \& Rocha, 2008).

Concorda-se com Dazzani (2010) acerca da importância da conscientização dos agentes escolares para que se compreenda que as concepções acerca de 
como os alunos com NEE aprendem influenciam suas práticas pedagógicas junto a este grupo. Barroco e Souza (2012) ratificam este ponto de vista, afirmando que existe uma relação entre as concepções e práticas dos profissionais e que estas formas de pensar e agir se configuram em resposta a um contexto histórico e sociocultural específico. Nesse sentido, é importante discutir e problematizar a temática da inclusão junto aos agentes escolares, em um trabalho articulado, levando-os a refletir sobre suas concepções e práticas, com vistas a oportunizar o delineamento de estratégias de intervenção que proporcionem a efetiva inclusão escolar e social das crianças com NEE, bem como estimulem o desenvolvimento de suas potencialidades (Schruber, \& Cordeiro, 2010).

Considerando que as práticas dos profissionais entrevistados podem ser influenciadas pelas concepções que possuem sobre o processo de inclusão escolar, realizou-se o levantamento dos referenciais teóricos adotados pelos psicólogos escolares para subsidiar suas práticas referentes à educação inclusiva. Foram mencionados Vygotsky (30\%), Piaget (20\%), Rogers, Paulo Freire, Freud e a linha sociointeracionista $(5 \%$ cada). Adverte-se para o fato de que citar autores como Vygotsky e Piaget não garante que estes realmente sejam utilizados como referenciais teóricos, uma vez que muitos psicólogos não levam para suas práticas uma compreensão mais aprofundada sobre estes referenciais teóricos (Lessa, \& Facci, 2011; Souza, \& Silva, 2009). Em menor frequência, foram citados os referenciais teóricos Wallon, Rubem Alves e Alicia Fernandes ( $2,5 \%$ cada). Cabe destacar que uma parcela dos entrevistados não especificou a abordagem teórica que orienta suas práticas $(2,5 \%)$, como ilustra a seguinte fala: "a gente mexe com tudo quanto é teoria".

Os resultados demonstram que os profissionais ainda recorrem, em parte, a um referencial teórico clínico para fundamentar suas ações junto ao grupo de crianças com necessidades educacionais especiais. Questiona-se o uso deste referencial junto ao referido grupo e suas repercussões no âmbito escolar, uma vez que, como pontuam Guzzo (2008; 2011) Souza e Rocha (2008) e Meira (2003), o embasamento teórico clínico remete a práticas consideradas inadequadas no ambiente escolar, a exemplo de diagnóstico e avaliação psicológica, dentre outras ações que promovem a psicologização de processos pedagógicos e não contemplam a investigação de processos socioculturais.
Em seguida, solicitou-se que psicólogos escolares e docentes descrevessem as ações desenvolvidas pela escola frente à inclusão escolar, sendo referida a realização de apoio psicopedagógico (55,3\% dos docentes e $37,6 \%$ dos docentes), encaminhamentos $(26,6 \%$ dos psicólogos e 8,3\% dos docentes), Conselho Educacional (13,3\% dos psicólogos), planejamento pedagógico de atividades e avaliações (6,6\% dos psicólogos e $16,6 \%$ dos docentes), Atendimento Educacional especializado e uso da sala de recursos (25\% dos docentes) e solicitação de cuidadoras (12,5\% dos docentes).

As práticas mencionadas enquadram-se no conceito de escola inclusiva apresentado por Luiz et al. (2008) e Mazzoni, Torres e Andrade (2001): escola que considera as necessidades individuais de cada estudante e caracteriza-se por flexibilidade do currículo e das formas de avaliação. Destaca-se que um modelo de inclusão escolar deve apresentar ações para todas as especificidades do corpo discente, e não apenas aos alunos com NEE, buscando proporcionar as relações em meio à diversidade humana (Anhão, Pfeifer, \& Santos, 2010).

A menção ao apoio psicopedagógico refere-se a relatos de atendimentos complementares e especializados, como observado no seguinte discurso: "temos também a sala de recurso; tem duas profissionais uma fica no turno da manhã e a outra no turno da tarde". A predominância desta resposta pode estar relacionada ao fato de que a Constituição garante não apenas o direito à educação, mas também ao chamado Atendimento Educacional Especializado (AEE), como pontua Luiz et al. (2008). Além disso, este tipo de resposta pode estar evidenciando, segundo Angelucci e Lins (2007) o conhecimento superficial, por parte de agentes escolares, dos referidos dispositivos jurídicos, o que dificulta a reflexão acerca de como podem contribuir para uma inclusão escolar efetiva.

A subcategoria planejamento pedagógico de atividades e avaliações $(6,6 \%)$ engloba ações educativas planejadas especialmente para os estudantes com NEE, como é ilustrado pela fala "as atividades a gente procura ser flexível, né, as avaliações também oralmente, o que a gente pode fazer pelo aluno a gente faz aqui na escola". Observa-se que a entrevistada declara planejar atividades e avaliações, não explicitando quais, nem como estas ações se efetivam. Neste sentido, Melo e Martins (2007) ressaltam que este tipo de prática deve compreender as ações realizadas dentro e fora de sala, como o 
próprio planejamento do professor, visando prestar suporte aos estudantes com NEE.

Ainda no que se refere às atividades realizadas pela escola, o discurso pode representar a falta de sistematização nos projetos de inclusão nas escolas visitadas. Exemplificando esta hipótese, foram observados discursos como "o professor tá sempre se esforçando ao máximo" e "olha, quase nenhuma atividade a escola realiza frente à inclusão, viu". O estudo realizado por Sant'Ana (2005) encontrou a mesma insatisfação com os apoios oferecidos pelos governos e pontuou a necessidade de uma relação mais próxima entre os profissionais que estão nas escolas e nas secretarias. Ainda a este respeito, Guiné (2004) acrescenta que as escolas brasileiras ainda prescindem de recursos e apoios para a implementação da proposta inclusiva.

Partindo destas dificuldades, Souza (2010) propôs um modelo de relação entre os governos e os profissionais da educação, efetuando um trabalho de mapeamento das visões e concepções dos psicólogos da rede, no estado de São Paulo. Neste trabalho, se atuou de forma a desenvolver práticas mais eficazes por parte dos psicólogos e se propôs que a intervenção em relação à queixa escolar seja direcionada em três etapas: a escola (professores, coordenação pedagógica), depois a família (horários e rotinas de estudo, ambiente de estudo estruturado) e os alunos (entre seus pares). Apenas se chegaria à etapa consecutiva caso a demanda não fosse solucionada nos níveis anteriores.

Realizou-se também a investigação das ações desenvolvidas pelos psicólogos escolares frente à inclusão escolar. Estas incluíram planejamento pedagógico $(28,1 \%)$, orientação a docentes e cuidadores $(18,7 \%)$, trabalhar o bullying/preconceito (12.5\%), encaminhamento (12,5\%), promoção de encontros com as crianças com NEE (12,5\%), orientação a pais $(9,3 \%)$ e escuta do aluno $(6,2 \%)$. Os profissionais de Psicologia também mencionaram como ações o trabalho com temáticas/projetos, em falas como "trabalhei as drogas", "trabalho as emoções, os valores", "trabalho com projetos" e "trabalho com pintura, com arte". Além disso, os referidos profissionais afirmaram realizar práticas com as crianças com NEE, a exemplo de "psicodiagnóstico"e "tratamento diferenciado".

A partir do exposto, considera-se importante verificar como e até que ponto os projetos implementados pelos psicólogos potencializam a aprendizagem e o desenvolvimento das crianças. Nesse sentido, Fleith (2011) alerta que as ações e os projetos de inclusão, sejam eles institucionais ou individuais, devem estar integrados, sistematizados e planejados cuidadosamente dentro de uma concepção de inclusão concatenada ao que a literatura aponta.

Outro aspecto levantado durante a realização do estudo consistiu nas ações desenvolvidas pelos docentes entrevistados frente à inclusão escolar. Dentre os docentes entrevistados, sete afirmaram realizar práticas direcionadas à inclusão de alunos com NEE, que consistem em: realização de atividades diferenciadas $(46,1 \%)$, maior acompanhamento durante a aula e a realização de atividades (23\%), estimular a coordenação motora $(15,4 \%)$ e realização de trabalhos em grupo $(15,4 \%)$.

A subcategoria realização de atividades diferenciadas refere-se a falas como "Dentro de sala de aula, eu tento fazer atividades diferenciadas [...], eu trabalho com caderno de desenho, aí eu tento fazer atividade com lápis colorido pra chamar a atenção, com figurinhas, com desenhos vazados". A subcategoria maior acompanhamento nos momentos de aula e de realização de atividades, por sua vez, é exemplificada pelo trecho "[...] o que a gente faz é chegar mais perto, é conversar, é mostrar, porque a gente, como professor, a gente não é trabalhada pra trabalhar com essas pessoas, então fica difícil pra gente saber que atitude tomar”. Pode-se pensar, a partir da fala, que há pouca especificidade e clareza das atividades e a ausência de menção de um trabalho articulado ou planejado que reflita uma proposta inclusiva. Por fim, a subcategoria realização de trabalhos em grupo ilustra discursos como "É mais a questão do trabalho em grupo mesmo e a gente vê mesmo que eles se empolgam para fazer as atividades junto com os colegas".

Ressalta-se a importância de verificar se estas práticas realmente favorecem o desenvolvimento e a aprendizagem dos estudantes com NEE, bem como de conscientizar os professores do papel fundamental que podem exercer no processo de inclusão escolar como mediadores do conhecimento, facilitadores das interações entre as crianças e coparticipantes das intervenções propostas pelos psicólogos escolares (Oliveira, \& Marinho-Araújo, 2009).

Os docentes destacaram como profissionais que poderiam ajudá-los no processo de inclusão escolar: psicólogo escolar (30,8\%), orientador escolar $(14,2 \%)$, professores $(14,2 \%)$, assistente social $(10,7 \%)$, cuida- 
dores $(7,1 \%)$, supervisor escolar $(3,5 \%)$, todos $(3,5 \%)$, direção $(3,5 \%)$, responsável pela sala de recursos $(3,5 \%)$ e psicopedagogo (3,5\%). A respeito da parceria estabelecida entre professores e psicólogos escolares, concordase com Martínez (2009) que há um “[...] compromisso dos psicólogos com a transformação dos processos educativos, com a efetivação das mudanças necessárias que demanda a melhoria da qualidade da educação no país" (p. 169). Diante disso, considera-se que a conscientização, por parte dos psicólogos, do papel que podem desempenhar frente à inclusão de estudantes com NEE nos contextos educacionais deve ter início na graduação (Pletsch, 2009). Nesta linha de raciocínio, defende-se que temas como processo ensino-aprendizagem, desenvolvimento humano, inclusão escolar, fracasso escolar e dicotomias normal/anormal devem ser contemplados na formação do (a) psicólogo (a).

A subcategoria todos é representada pelo discurso "Eu aprendi que a escola é uma equipe. É o professor que ajuda o porteiro, porteiro que ajuda professor, professor que ajuda a direção, é um trabalho em conjunto. Todos poderiam ajudar. Basta ter vontade pra isso e quererem fazer acontecer, né. Todos poderiam ajudar". Esta fala evidencia a importância que os psicólogos escolares estabeleçam parcerias com os demais agentes educativos, principalmente com docentes e pedagogos, no sentido de ajudá-los a diversificar, aprimorar e contemplar práticas inclusivas e a desenvolver habilidades sociais que oportunizem um melhor relacionamento com os estudantes, principalmente aqueles que apresentam queixas escolares ou NEE (AlmeidaVerdu et al., 2002; Silva, \& Mendes, 2012).

Alerta-se para a fala de um docente acerca da formação de parcerias com psicopedagogos:

[...] eu acho essencial o psicopedagogo também estar na escola. Eu estou fazendo especialização em psicopedagogia, eu considero que todo professor deveria ter essa capacitação. Agora tem uma certa rivalidade entre psicologia e a psicopedagogia, eu não entendo isso, eu acho assim que o que o psicopedagogo faz tá fora das competências do psicólogo. O psicólogo faz muita coisa ele trabalha a escola como um todo enquanto o psicopedagogo foca no próprio aluno na questão específica da aprendizagem. Ai, graças a Deus aqui psicólogo tem a mesma visão, olha que engraçado, né.
Diante deste relato, alerta-se para a importância de que o psicólogo escolar esteja consciente de suas capacidades e potencialidades de ação, bem como esclareça suas atribuições e possibilidades de ação junto aos demais agentes educativos. Como afirma Solís (2011), o psicopedagogo não possui as competências e a qualificação adquiridas durante a formação em Psicologia e que são essenciais para uma compreensão mais ampla do processo de ensino-aprendizagem. Portanto, não seria o profissional mais indicado para lidar com as dificuldades no processo de escolarização.

Por fim, indagou-se aos docentes sobre quais recursos favoreceriam a aprendizagem dos alunos com NEE, obtendo-se como respostas: sala de recursos $(27,8 \%)$, recursos humanos $(16,7 \%)$, jogos pedagógicos $(11,1 \%)$, material lúdico $(11,1 \%)$, sala de informática $(11,1 \%)$, aulas bem preparadas $(5,5 \%)$, recursos audiovisuais (5,5\%), atividades significativas $(5,5 \%)$ e estrutura física (5,5\%). A este respeito, concorda-se com Dorziat (2009) que os elementos que tornam possível sucesso efetivo do processo inclusivo devem envolver um ambiente adaptado às suas necessidades, bem como abordagem de ensino e adaptações curriculares adequadas. A autora complementa que tais fatores não devem ser considerados unicamente para as crianças com deficiência, mas para todas aquelas que necessitem de um currículo adequado à sua individualidade e que a escola deve investir no treinamento de seus agentes escolares, a fim de capacitá-los a lidar com a criança com necessidades educacionais especiais.

Deve-se atentar para o fato de que as crianças não devem ser simplesmente alocadas às salas de aula junto àquelas que apresentam desenvolvimento típico. É necessário que a escola crie condições favoráveis para recebê-las, ou seja, que proporcione não uma educação integrada, no sentido de apenas possibilitar a convivência do estudante com NEE com os demais, mas que promova a educação inclusiva, em que não é a criança que deve se adaptar à vida escolar, mas é a escola que deve ser alterada para o acolhimento das diferenças e potencialidades (Crochík et al., 2009).

\section{Considerações finais}

Este estudo teve como principal objetivo conhecer como psicólogos escolares e docentes de instituições públicas de ensino da cidade de João 
Pessoa-PB concebem a inclusão escolar e atuam nesta perspectiva. Especificamente, buscou-se também identificar o grupo de alunos com quem estes profissionais trabalham, os referenciais teóricos utilizados pelos psicólogos para orientar suas práticas, os recursos/atividades que favoreceriam a aprendizagem de alunos com NEE e as ações dos respectivos profissionais e das escolas.

Os principais resultados obtidos evidenciaram que as concepções acerca da inclusão escolar dos psicólogos entrevistados variam desde percepções próximas da perspectiva inclusiva a definições mais superficiais, atravessadas por enfoques de mera inserção educacional. O discurso da maioria dos participantes evidencia uma posição favorável à inclusão escolar dos alunos com necessidades educacionais especiais na educação comum, talvez por se tratar de um tema atualmente discutido e valorizado tanto na academia como no meio social. Ainda observou-se, por meio dos relatos objetivos, que os profissionais têm pouca clareza a respeito das ações que favoreceriam o processo de aprendizagem.

Os relatos dos psicólogos, em sua maioria, parecem revelar a viabilidade da educação inclusiva. No entanto, para eles, esta apresentaria muitas dificuldades e mitos a serem quebrados. Os psicólogos entrevistados apontaram sentimentos de frustração e se mostraram cientes da necessidade de uma melhor preparação ou embasamento teórico-prático para atuar junto a estudantes com necessidades educacionais especiais. Parte deles afirmou não ter aprendido as práticas educacionais essenciais à promoção da inclusão durante a formação acadêmica e relatou precisar do apoio de especialistas.

Em ambos os grupos de profissionais entrevistados, principalmente o dos docentes, foi reconhecida a importância de uma educação democrática, embora tenham apontado que os órgãos administrativos competentes e a universidade devem intensificar os subsídios e apoio a sua prática. Os professores se queixam de não terem subsídios teóricos e apoios suficientes para ensinar em salas de aulas com crianças com necessidades especiais, o que também foi verificado no estudo de Sant'Ana (2005). Diante desta realidade, destaca-se o argumento de Fleith (2011) de que muitas vezes os psicólogos escolares não estão acolhendo a demanda destes docentes, tampouco respondendo a esta demanda de forma satisfatória, em consequência de uma formação que ainda pouco discute temas como inclusão e necessidades educacionais especiais.

Concorda-se com a referida autora que o psicólogo escolar pode ser um forte agente transformador quando obtém conhecimento do seu papel e de como realizá-lo, promovendo ações que destaquem o respeito às diferenças, ajudando a construir um ambiente favorável à inclusão e trabalhando de modo integrado junto aos demais agentes escolares, tanto no sentido de promover reflexões como de delinear estratégias interventivas.

Entende-se ainda que uma imersão politicamente consciente do profissional da Psicologia pode ocorrer quando ele vivencia a rotina dos membros da comunidade escolar e age como um mediador que propicia o desenvolvimento humano na escola. Cabe ao psicólogo principalmente promover a desconstrução de mitos através de aprofundamento teórico para essa demanda. Considera-se, então, importante uma formação continuada que subsidie o trabalho do psicólogo no sentido de propor estratégias psicopedagógicas junto à equipe de docentes e auxiliares de sala (Dazzani, 2010; Fleith, 2011; Rossato, \& Leonardo, 2012).

Ressalta-se, ainda, a necessidade de mais estudos sobre a inclusão escolar, pois, apesar de ser muito defendida e estudada, ainda são poucas as referências que disponibilizam, aos profissionais da educação, intervenções no campo da Psicologia Inclusiva. Recorre-se, neste aspecto, ao estudo realizado por Almeida-Verdu et al. (2002), que propõe, como intervenção frente à inclusão escolar: interagir com coordenador pedagógico; criar espaços de discussão dos temas relacionados à inclusão escolar entre docentes e equipes pedagógicas; realizar reuniões bimestrais com os pais; realizar atividades diretas em sala de aula com os alunos; e delinear, junto aos professores, práticas que podem desenvolver junto às crianças com NEE. Desta forma, compreende-se a inclusão como um conjunto de ações específicas e integradas e considera-se que a instituição escolar deve fornecer o suporte necessário para que o aluno com necessidades educacionais especiais adquira as habilidades sociais e acadêmicas que usualmente são aprendidas no contexto escolar.

É importante, também, afirmar que as escolas devem promover não só o acesso, mas também a permanência e o sucesso para todos os alunos, com e sem necessidades educacionais especiais. Como proposto por Barbosa e Moreira (2009), não se deve, 
em nome de uma ideologia homogeneizante, negar as diferenças individuais, os déficits e/ou as elevadas eficiências, a deficiência intelectual e/ou as altas capacidades intelectuais.

Pontua-se a relevância de estudos que enfatizam esta temática no sentido de promover uma maior compreensão e mobilizar práticas na interface Psicologia Escolar - Educação Inclusiva. Destaca-se também a importância dos diversos aportes da Psicologia do Desenvolvimento, da Psicologia da Aprendizagem e da Psicologia Social, além do entendimento das políticas públicas, para subsidiar as ações dos profissionais no campo educacional. Defende-se que estudos como este vêm a contribuir para a formação e a atuação consciente de psicólogos nos mais diversos

\section{Referências}

Almeida-Verdu, A. C. M.; Fernandes, M. C., \& Rodrigues, O. M. P. R. (2002). A inclusão de pessoas com necessidades educativas especiais: implementação de práticas inclusivas e aspectos de planejamento educacional. Interação em Psicologia, 6(2), 223-232. doi:10.5380/psi.v6i2.3310

Anhão, P.P. G.; Pfeifer, L. L., \& Santos, J. L. (2010). Interação social de crianças com Síndrome de Down na educação infantil. Revista Brasileira de Educação Especial, 16(1), 31-46. doi:10.1590/S1413-65382010000100004

Angelucci, C. B., \& Lins, F. R. S. (2007). Pessoas significativamente diferentes e o direito à educação: uma relação atravessada pela queixa. In B. P. Souza (Org.), Orientação à queixa escolar (pp. 329-349). São Paulo, SP: Casa do Psicólogo.

Barbosa, A. J. G., \& Moreira, P. S. (2009). Deficiência mental e inclusão escolar: produção científica em Educação e Psicologia. Revista Brasileira de Educação Especial, 15(2), 337-352. doi:10.1590/S1413-65382009000200011

Bardin, L. (2008). Análise de conteúdo. Lisboa: Edições 70.

Barroco, S. M. S., \& Souza, M. P. R. (2012). Contribuições da Psicologia Histórico-Cultural para a formação e atuação do psicólogo em contexto de Educação Inclusiva. Psicologia USP, 23(1), 111-132. doi:10.1590/S0103-65642012000100006

Batista, M. W., \& Enumo, S. R. F. (2004). Inclusão escolar e deficiência mental: análise da interação social entre companheiros. Estudos de Psicologia, 9(1), 101-111. doi:10.1590/S1413-294X2004000100012 contextos sociais, em especial nos contextos educacionais que possuem como função maior ser promotores do desenvolvimento e aprendizado humano.

Os resultados deste estudo revelaram, ainda, a necessidade de uma formação que habilite os psicólogos a lidarem com as demandas escolares no sentido de promover processos de inclusão escolar e social e de possibilitar a coadunação entre a prática e os avanços teóricos e metodológicos da Psicologia Escolar Educacional. Nesta linha de raciocínio, defende-se que temas como processos de ensino e aprendizagem, desenvolvimento humano, "dicotomia normal/anormal”, inclusão escolar e necessidades educacionais especiais sejam mais contemplados e discutidos na formação do (a) psicólogo (a).

Briant, M. E. P., \& Oliver, F. C. (2012). Inclusão de crianças com deficiência na escola regular numa região do município de São Paulo: conhecendo estratégias e ações. Revista Brasileira de Educação Especial, 18(1), 141-154. doi:10.1590/S1413-65382012000100010

Carvalho, R. E. (1993). A política da educação especial no Brasil. Em Aberto, 13(60), 93-102. Recuperado de http://emaberto.inep.gov.br/index.php/emaberto/ article/view/1919

Cavallari, J. S. (2010). O equívoco no discurso da inclusão: o funcionamento do conceito de diferença no depoimento de agentes educacionais. Revista Brasileira de Lingüística Aplicada, 10(3), 667 -680. doi:10.1590/S1984-63982010000300009

Crochík, J. L., Casco, R., Ceron, M., \& Catanzaro, F. O. (2009). Relações entre preconceito, ideologia e atitudes frente à educação inclusiva. Estudos de Psicologia, 26(2), 123-132. doi:10.1590/S0103-166X2009000200001

Dazzani, M. V. M. (2010). A psicologia escolar e a educação inclusiva: uma leitura crítica. Psicologia: Ciência e Profissão, 30(2), 362-375. doi:10.1590/S1414-98932010000200011

Dorziat, A. (2009). A inclusão nas escolas de $1^{\circ}$ ciclo de ensino básico de Lisboa: algumas considerações. Revista Brasileira de Educação Especial, 15(2), 269-288. doi:10.1590/S1413-65382009000200007

Facci, M. G. D., \& Eidt, N. M. (2011). Formação do psicólogo para atuar na instituição de ensino: a queixa escolar em questão. In: R. G. Azzi, \& M. H. T. A. Gianfaldoni (Orgs.), Psicologia e educação (pp. 9-32). São Paulo, SP: Casa do Psicólogo. 
Fragoso, F. M. R. A., \& Casal, J. (2012). Representações sociais dos educadores de infância e a inclusão de alunos com necessidades educativas especiais. $R e$ vista Brasileira de Educação Especial, 18(3), 527-546. doi:10.1590/S1413-65382012000300011

Fleith, D. S. (2011). A Política Nacional de Educação Especial na perspectiva da educação inclusiva: desafios para o psicólogo escolar. In R. S. L. Guzzo, \& C. M. Marinho-Araújo (Orgs.), Psicologia escolar: identificando e superando barreiras (pp. 33-46). Campinas, SP: Alínea.

Guiné, C. (2004). Avaliação psicopedagógica. In C. Coll, A. Marchesi, \& J. Palacios (Orgs.), Desenvolvimento psicológico e educação: transtornos de desenvolvimento e necessidades educativas especiais (pp. 275-289). Porto Alegre, RS: Artmed.

Guzzo, R. S. L. (2011). Desafios cotidianos em contextos educativos: a difícil formação de psicólogos para a realidade brasileira. In R. G. Azzi, \& M. H. T. A. Gianfaldoni, Psicologia e educação (pp. 253-270). São Paulo, SP: Casa do Psicólogo.

Guzzo, R. S. L. (2008). Formando psicólogos escolares no Brasil, dificuldades e perspectivas. In S. M. Wechsler (Org.), Psicologia escolar: pesquisa, formação e prática (pp. 75-92). Campinas, SP: Alínea.

Kafrouni, R., \& Pan, M. A. G. S. (2001). A inclusão de alunos com necessidades educativas especiais e os impasses frente a capacitação dos profissionais da educação básica: um estudo de caso. Interação em Psicologia, 5, pp. 31-46. doi:10.5380/psi.v5i1.3316

Leonardo, N. S. T. (2008). Inclusão escolar: um estudo acerca da implantação da proposta em escolas públicas. Psicologia Escolar e Educacional, 12(2), 431-440. doi:10.1590/S1413-85572008000200014

Lessa, P. V., \& Facci, M. G. D. (2011). A atuação do psicólogo no ensino público do Estado do Paraná. Psicologia Escolar e Educacional, 15(1), 131-141. doi: 10.1590/S1413-85572011000100014

Luiz, F. M. R., Bortoli, P. S., Floria-Santos, M., \& Nascimento, L. C. (2008). A inclusão da criança com Síndrome de Down na rede regular de ensino: desafios e possibilidades. Revista Brasileira de Educação Especial, 14(3), 497-508. doi:10.1590/S1413-65382008000300011

Martínez, A. M. (2009). Psicologia escolar e educacional: compromissos com a educação brasileira. Psicologia Escolar e Educacional, 13(1), 169-177. doi:10.1590/S1413-85572009000100020
Mazzoni, A. A., Torres, E. F., \& Andrade, J. M. B. (2001). Admissão e permanência de estudantes com necessidades educativas especiais no ensino superior. Acta Scientiarum, 23(1), 121-126. Recuperado de http://periodicos.uem.br/ojs/index.php/ActaSciHumanSocSci/article/view/2751

Meira, M. E. M. (2003). Construindo uma concepção crítica de psicologia escolar: contribuições da pedagogia histórico-crítica e da psicologia sócio-histórica. In M. E. M. Meira, \& M. A. Antunes (Orgs.), Psicologia escolar: teorias críticas (14-77). São Paulo, SP: Casa do Psicólogo.

Melo, F. R. L. V., \& Martins, L. A. R. (2007). Acolhendo e atuando com alunos que apresentam paralisia cerebral na classe regular: a organização da escola. $R e-$ vista Brasileira de Educação Especial, 13(1), 111-130. doi:10.1590/S1413-65382007000100008

Oliveira, C. B. E., \& Marinho-Araújo, C. M. (2009). Psicologia escolar: cenários atuais. Estudos e Pesquisas em Psicologia, 9(3), 648-663. Recuperado de http:// www.e-publicacoes.uerj.br/index.php/revispsi/article/view/9075/7475

Pletsch, M. D. (2009). A formação de professores para a educação inclusiva: legislação, diretrizes políticas e resultados de pesquisas. Educar em Revista, (33), 143156. doi:10.1590/S0104-40602009000100010

Rossato, S. P. M., \& Leonardo, N. S. T. (2012). A queixa escolar na perspectiva de educadores da Educação Especial. Psicologia Escolar e Educacional, 16(1), 15-23. doi:10.1590/S1413-85572012000100002

Sant'Ana, I. M. (2005). Educação inclusiva: concepções de professores e diretores. Psicologia em Estudo, 10(2), 227-234. doi:10.1590/S1413-73722005000200009

Schruber, J., \& Cordeiro, A. F. M. (2010). Educação inclusiva: desafios do estágio curricular supervisionado em Psicologia Escolar/Educacional. Psicologia: Ensino e Formação, 1(1), 21-29. Recuperado de http://pepsic.bvsalud.org/scielo.php?script=sci_arttext\&pid=S2177-20612010000100003

Sekkel, M. C., Zanelatto, R., \& Brandão, S. B. (2010). Uma questão para a educação inclusiva: expor-se ou resguardar-se? Psicologia Ciência e Profissão, 30(2), 296-307. doi:10.1590/S1414-98932010000200006

Silva, A. M., \& Mendes, E. G. (2012). Psicologia e inclusão escolar: novas possibilidades de intervir preventivamente sobre problemas comportamentais. $R e$ vista Brasileira de. Educação Especial, 18(1), 53-70. doi:10.1590/S1413-65382012000100005 
Solís, M. P. (2011). ¿Puede um psicopedagogo desempeñar el rol del psicólogo educativo? profesionalización frente al intrusismo profesional. Estudos de Psicologia (Campinas), 28(1), 3-13. doi:10.1590/S0103-166X2011000100001

Souza, M. P. R. (2010). Atuação do psicólogo na rede pública de educação: concepções, práticas e desafios (Tese de livre docência). São Paulo, SP: Instituto de Psicologia da Universidade São Paulo.

Souza, M. P. R., \& Rocha, M. L. (2008). Políticas Educacionais: legislação, formação profissional e participação democrática. In: Conselho Federal de Psicologia, O ano da psicologia na educação: textos geradores (pp. 27-52). Brasília, DF: Conselho Federal de Psicologia.

Souza, M. P. R., \& Silva, S. M. C. da (2009). A atuação do psicólogo na rede pública de educação frente à demanda escolar: concepções, práticas e inovações. In C. M. Marinho-Araújo (Org.), Psicologia escolar: novos cenários e contextos de pesquisa, prática e formação (pp. 75-105). Campinas, SP: Alínea.

Vygotsky, L. S. (1997). Obras escogidas: fundamentos de defectología. Madrid: Visor.

Wanderer, A., \& Pedroza, R. L. S. (2010). Elaboração de projetos político-pedagógicos: reflexões acerca da atuação do psicólogo na escola. Psicologia Escolar e Educacional, 14(1), 121-129. doi:10.1590/S1413-85572010000100013

Fabiola de Sousa Braz-Aquino

Docente da Universidade Federal da Paraíba, João Pessoa - PB. Brasil.

E-mail: fabiolabrazaquino@gmail.com
Ingrid Rayssa Lucena Ferreira

Psicóloga pela Universidade Federal da Paraíba, João Pessoa - PB. Brasil.

\section{Lorena de Almeida Cavalcante}

Mestrado em Psicologia Social pelo Programa de Pós-graduação em Psicologia Social da Universidade Federal da Paraíba, João Pessoa - PB. Brasil.

Endereço para envio de correspondência:

Universidade Federal da Paraíba, Centro de Ciências Humanas Letras e Artes - Campus I. CEP: 58059-900. João Pessoa - PB. Brasil.

Recebido: 03/04/2014

Reformulação: 28/10/2015

Aprovado: 03/04/2016

Received: 04/03/2014

Reformulação: 10/28/2015

Approved:04/03/2016

Recibido: 03/04/2014

Reformulação: 28/10/2015

Aceptado: 03/04/2016

Como citar: Aquino, F. S. B., Ferreira, I. R. L., \& Cavalcante, L. A. (2016). Concepções e práticas de psicólogos escolares e docentes acerca da inclusão escolar. Psicologia: Ciência e Profissão, 36(2): 255-266. doi:10.1590/1982-3703000442014

How to cite: Aquino, F. S. B., Ferreira, I. R. L., \& Cavalcante, L. A. (2016). Conceptions and practices, on school inclusion, of school psychologists and teachers. Psicologia: Ciência e Profissão, 36(2): 255-266. doi:10.1590/1982-3703000442014

Cómo citar: Aquino, F. S. B., Ferreira, I. R. L., \& Cavalcante, L. A. (2016). Conceptos y prácticas de profesores y psicólogos escolares sobre inclusión escolar. . Psicologia: Ciência e Profissão, 36(2): 255-266. doi:10.1590/1982-3703000442014 